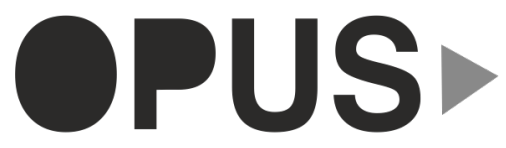

Uluslararası Toplum Araştırmaları Dergisi International Journal of Society Researches
E-ISSN : 2528-9535

YIl Year: 11

Cilt Volume: 18

Sayı Issue :Yönetim ve Organizasyon Özel Sayısı

Temmuz July 2021

Makalenin Geliş Tarihi Received Date: 30/09/2020

Makalenin Kabul Tarihi Accepted Date: 07/06/2021

\title{
Türkiye'de Para ve Maliye Politikalarının Göreli Etkinliği: SVAR Analizi
}

DOI: $10.26466 /$ opus. 802682

*

\section{İzzettin Ulusoy*}

* Dr. Öğr. Üyesi, Hatay Mustafa Kemal Üniversitesi, Antakya MYO, Hatay/Türkiye

E-Posta: iulusoy3144@gmail.com

ORCID: $\underline{0000-0001-6464-7995}$

\begin{abstract}
Öz
İktisadi politikalara duyulan ihtiyaçlar, makro iktisat düzeyinde yapılmakta olan tartışmaların başındadır. Genellikle, Yeni Klasik Kuram ile Keynesyen Kuram arasında süren tartısmalar, son zamanlarda para politikaları üzerinden yapılmakta ve maliye politikalarım çok fazla dikkate almamışlardır. Gerek iktisadi aktivite seviyesini gerekse enflasyonu kontrol altına alma hususunda, para politikalarm maliye politikalarına nazaran daha çok ağırlık veren ekonomistler, para politikası ağırlıklı istikrar paket programların etkin oldukların ileri sürmüşlerdir. Maliye ve para politikalarını göreli etkinliği iktisatçlar tarafindan tartışlan fakat söz konusu konu üzerinde hemfikir olunamayan bir konudur. Söz konusu konunun temelinde Kenesyen-Monetarist düşünce tartışmaları bulunmaktadır. Keynesyen ekol maliye politikasl; Monetaris ekol ise para politikası üzerinde ağırlık vermişlerdir. Çalışmada, Türk ekonomisinde maliye ve para politikalarının iktisadi büyüme üzerindeki etkisi incelenmiştir. 2005:04-2020:02 yıllar arasında çeyrek verileri içeren iktisadi büyüme, para arzı ve gelir değişkenleri kullanılmıştır. Bu değiş̧kenler yardımıyla para ve maliye politikalarmın iktisadi büyümeye etkileri SVAR yöntemiyle incelenmiştir. Analizde kullanılan değişkenler Türkiye Cumhuriyet Merkez Bankasından alınmış, E-Views 10 paket programı kullanılmıştır. Elde edilen ampirik bulgular sonucunda, Türkiye ekonomisindeki büyümede hem maliye hem para politikaları etkin olduğu görülmüştür.
\end{abstract}

Anahtar Kelimeler: Para Politikası, Maliye Politikası, Yapısal SVAR, Monetarist Ekol, Keynesyen Ekol. 


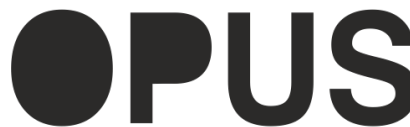

Uluslararası Toplum Araştırmaları Dergisi International Journal of Society Researches
E-ISSN : 2528-9535

YIl Year: 11

Cilt Volume: 18

Sayı Issue :Yönetim ve Organizasyon Özel Sayısı

Temmuz July 2021

Makalenin Gelis Tarihi Received Date: 30/09/2020

Makalenin Kabul Tarihi Accepted Date: 07/06/2021

\title{
Relative Effectiveness of Monetary and Fiscal Policy in Turkey: SVAR Analysis
}

*

\begin{abstract}
The need for economic policies is at the top of the discussions at macroeconomic level. Generally, the discussions between New Classical Theory and Keynesian Theory have been made over monetary policies recently and they have not taken the fiscal policies into account. Economists, who put more emphasis on monetary policies than fiscal policies in terms of controlling both the level of economic activity and inflation, claimed that they are effective in monetary policy-based stabilization programs. The relative effectiveness of fiscal and monetary policies is an issue discussed by economists, but cannot be agreed on. Keynesian-Monetarist thought discussions are at the heart of the subject. Keynesian School fiscal policy; Monetaris School, on the other hand, focused on monetary policy. In the study, the effect of fiscal and monetary policies on economic growth in the Turkish economy is examined. Economic growth, money supply and income variables including quarterly data between 2005: 04-2020: 02 were used. With the help of these variables, the effects of monetary and fiscal policies on economic growth were analyzed using the SVAR method. The variables used in the analysis were taken from the Central Bank of Turkey, 10 EViews software package is used. As a result of the empirical findings, the growth of Turkey's economy, both fiscal and monetary policies were found to be effective.
\end{abstract}

Keywords: $\quad$ Monetary Policy, Fiscal Policy, Structural SVAR, Monetarist Ekol, Keynesian Ekol. 


\section{Giriş}

Maliye ve para politikaları, iktisadi politikalarının ana dallarını meydana getirmektedir. İktisat politikaları, hükümetlerin birkaç ekonomi araçlarını kullanarak belirli iktisadi hedeflere ulaşma çabalarıdır. İktisat politikalarıyla hedeflenilen amaçlar; hızlı iktisadi büyüme, yüksek istihdam ve fiyat istikrarıdır. $\mathrm{Bu}$ bağlamda, belirlenen hedeflere ulaşabilmek için kullanılmakta olan politikalar ve kullandıkları araçlar maliye ve para politikalarıdır. Para politikaları, paranın maliyetini ve miktarını, hane halklarıyla firmaların beklentilerini etkileyerek esas iktisadi hedeflere ulaşmaya dönük oluşturulan stratejilerdir (Önder, 2005, s.4). Maliye politikaları da esas iktisadi hedeflere ulaşmak maksadıyla kamu gelir ve harcamalarının büyüklük ve bileşiminde yapılması gerekli olan düzenlemelerdir (Ataç, 2009, s.36).

İktisat politika hedeflerine ulaşabilmek bakımından maliye ya da para politikalarının daha etkin ve geçerli olduğu iktisat literatürlerinde tartışılmakta olan konuların başında yer almaktadır. Bu bağlamda, 1960 'lı ve 1970'li yıllarda Monetarist ve Keynesyen iktisatçılar sürekli tartışmıştır (Kretzmer, 1992, s.21). Söz konusu tartışmalarda Keynesyen iktisatçılar maliye politikalarının daha etkin olduğunu ileri sürerlerken, Monetarist iktisatçılar ise para politikalarının daha etkin olduğunu ileri sürmüşlerdir. Ayrıca, iktisadi politika hedeflerine ulaşmada para politikalarının etkin olmadığını savunan Keynesyen iktisatçılar ile maliye politikalarının etkin olmadığını savunan Monetarist iktisatçılar da vardır (Cengiz, 2008, s.124). Bu bağlamda, 1960'lı ve 1970'li yıllarda pek çok ampirik çalışmalar yapılmıştır. Günümüzde bu çalışmaların sonucunda maliye ve para politikalarının etkinliklerine ilişkin olumsuz olduğu görüşüne inanan çok fazla iktisatçı olmasada, politikanın göreli etkinliklerine ait tartışmalar devam etmektedir.

Çalışmanın amacı, Türkiye'de 2005:04-2020:02 dönemleri arasında çeyreklik veriler kullanılarak para ve maliye politikalarının etkinliğini yapısal SVAR yöntemini kullanarak incelemektir. Bu bağlamda çalışmada iktisadi büyüme, GSYH ve para arzı değişkenleri kullanılmıştır. Çalışmanın ilk bölümünde literatür çalışmasına değinilmiştir. İkinci bölümde çalışmada kullanılan metot ve veri setleri açıklanmıştır. Üçüncü bölümde ampirik analiz sonuçları açıklanmıştır. Son bölümde ise 
çalışmanın analiz sonuçları yorumlanmış ve elde edilen sonuçlar değerlendirilmiştir.

\section{Literatür Taraması}

Monetarist ve Keynesyen iktisatçıların maliye ve para politikası etkinlikleri konusunda farklı görüşleri vardır. Bu garklılıllar daha çok para talebi ve yatırımların faiz esnekliklerine ilişkin ileri sürülen görüşlerin farklı olmasından kaynaklanıyor. Keynesyen iktisatçılar, para talebinin faiz esnekliği yüksek ve yatırımların faiz esnekliği düşük olduğunu ileri sürerken, Monetarist iktisatçlar aksi görüş ileri sürmektedir. Para talebinin faiz esnekliği yüksek ve yatırımların faiz esnekliği düşükse, para arzında meydana gelen bir artış, faiz oranını önemli ölçüde düşürecektir. Fakat faiz oranındaki bu düşüşler, yatırımları sınırlı düzeylerde uyaracaktır. Bu bağlamda, maliye politikalarıyla kamu harcamalarında artışlar ya da vergilerde indirimlere gidilerek toplam talepte para politikalarına nazaran daha fazla bir artış sağlanılacaktır. Para talebinin faiz esnekliği düşük ve yatırımların faiz esnekliği yüksekse, para arzındaki herhangi bir artış faiz oranında sınırlı bir düşüşe yol açacaktır. Fakat faiz oranındaki bu düşüşler yatırımları daha çok uyaracaktır. Bu açıdan bakıldığında, para politikaları etkindir şeklinde ifade edilebilmektedir. Dolayısıyla maliye politikaları, faiz oranlarında meydana gelen artışlar yüzünden, bir kısım özel sektör yatırımlarını azaltarak dışlama etkisine neden olmasından dolayı etkin değildir (Fischer and Rudiger,1998, s.160).

Hall ve Henry (1999), Nash dengesini kullanarak yaptıkları araştırmalarında maliye ve para politikaları arasında koordinasyonun sağlanılamaması durumunda daha düşük bir iktisadi büyüme gerçekleşeceğini ifade etmişlerdir. Ayrıca, maliye ve para politikalarının koordinasyonu sağlanılamazsa aşırı değerli döviz kurlarının olacağını ve net dış ticaret üzerinde negatif bir etkiye yol açacağı sonucunu elde etmişlerdir.

Hanif ve Arby (2003), etkin bir maliye ve para politika koordinasyonlarının olmadığı bir ortama bağlı olarak meydana gelebilecek finansal istikrarsızlıklar; iktisadi büyümeye, yüksek faiz oranlarına, yüksek enflasyona ve döviz kuru baskısına negatif olarak yansımasına neden olacaktır. Analiz bulguları neticesinde etkin bir maliye ve para poli- 
tikaları için iktidarla Merkez Bankası'nın koordinasyon içerisinde olması kaçınılmazdır.

Dikmen (2006), 1987-2003 yıllarına ait yıllık veriler kullanarak St. Louis modelini Türkiye'ye uygulamış ve elde ettiği ampirik bulgular neticesinde para politikalarının maliye politikalarından daha etkin olduğu sonucunu elde etmiştir.

Panico vd. (2008), paranın nötr olduğunu ve maliye ile para politikaları arasında koordinasyon sağlanılmasına gerek olmadığını savunmuşlardır. Monetarist iktisatçların benimsedikleri görüşleri baz alarak 1970'li yıllarda uygulanan maliye ve para politikalarının etkisiyle faiz oranları yükselmiş ve sonuçta işsizlik artmış, bazı ülkelerde dış borçlar da artışlar yaşanmıştır. Bu olumsuz tablo, 1980'li yıllara gelindiğinde izlenilen maliye ve para politikaları terk edilmiş ve politikalar arasındaki koordinasyon ön plana çıkmış, maliye ve para politikalarının birlikte uygulanması fikrinde birleşilmiştir.

Düzgün (2010), 1987-2007 yıllarına ait çeyreklik veriler kullanara Türkiye'de maliye ve para politikalarının etkinliğini nedensellik ve hata düzeltme modeli yöntemini kullanarak incelemiştir. Elde edilen ampirik bulgular neticesinde, maliye politikalarının para politikalarından daha etkin olduğu sonucuna ulaşmıştır. Ancak, Düzgün'ün çalışmasında maliye politikaları değişkeninin iktisadi büyüme üzerindeki etkisi negatif çıkmış ve maliye politikalarının da etkin olmadığı sonucunu elde etmiştir. Karaca (2017), 2004-2017 yıllarına ait üçer aylık verilerle Türkiye'de maliye ve para politikalarının etkinliğini VAR modeli analizi yardımıyla incelemiş ve para politikalarının maliye politikalarından daha etkin olduğu sonucunu elde etmiştir.

\section{Model, Veri Seti ve Yöntem}

Yapılan literatür incelemelerinde analiz yönteminde farklılığa gidilerek çalışmada Yapısal SVAR yöntemine başvurulmuştur. Aktaş'a göre, VAR modelleri değişkenler arasında oluşan bağlantıların meydana gelmesi Leroy ve Cooley (1985) ile Bernanke (1986) tarafından tartışılmaya başlanmış ve SVAR modeli kullanımına geçmiştir. Yapısal şoklar iktisat teorilerine dayanan kısıtlar için yapısal VAR modellerini kullanmaktadır. 
Leroy ve Cooley (1985) VAR yönteminde, teorilerin araştırılması ve modellerin test edilmesi sonucu etki-tepki grafikleri ve şokların yeterli seviyelerde modeli açıklamadığını göstermiştir. Dolayısıyla iktisadi politika değerlendirmelerde VAR modellerinin yetersiz olduğunu belirtmiştir.

SVAR modelleri sisteme uygulanan kısitların eklenmesiyle iktisadi kuramların ileri sürdüğ̈̈ hipotezler doğrultusunda kurulmaktadır. (Saraç, 2012, s.86). Bu hipotezlerin açıklanmasında VAR modellerindeki yapısal şokların VEC arasındaki ilişki aşağıda gösterilmiştir:

$\left[\begin{array}{ccccc}1 & b_{12} & b_{13} & \ldots & b_{1 n} \\ b_{21} & 1 & b_{23} & \ldots & b_{2 n} \\ \ldots & \ldots & \ldots & \ldots & \ldots \\ b_{n 1} & b_{n 2} & b_{n 3} & \ldots & b_{n n}\end{array}\right]\left[\begin{array}{c}x_{1 t} \\ x_{2 t} \\ \ldots \\ x_{n t}\end{array}\right]=\left[\begin{array}{c}b_{10} \\ b_{20} \\ \ldots \\ b_{n 0}\end{array}\right]+\left[\begin{array}{ccccc}\gamma_{11} & \gamma_{12} & \gamma_{13} & \ldots & \gamma_{1 n} \\ \gamma_{21} & \gamma_{22} & \gamma_{23} & \ldots & \gamma_{2 n} \\ \ldots & \ldots & \ldots & \ldots & \ldots \\ \gamma_{n 1} & \gamma_{n 2} & \gamma_{n 3} & \ldots & \gamma_{n n}\end{array}\right]\left[\begin{array}{c}x_{1 t-1} \\ x_{2 t-1} \\ \ldots \\ x_{3 t-1}\end{array}\right]+\left[\begin{array}{c}\varepsilon_{1 t} \\ \varepsilon_{2 t} \\ \ldots \\ \varepsilon_{n t}\end{array}\right]$

Aşağıdaki denklemde SVAR modeline ait kapalı bir form eşitliği belirtilmiştir. İki tarafı $\beta^{-1}$ ile çarparsak matrsis ve kapalı formlar elde edilecektir. (2.2) no'lu denlemde matris formu, (2.3) no'lu denklemde ise kapalı form belirtilmektedir:

$$
\begin{aligned}
& {\left[\begin{array}{l}
y_{\mathrm{t}} \\
z_{\mathrm{t}}
\end{array}\right]=\left[\begin{array}{cc}
1 & -b_{12} \\
-b_{21} & 1
\end{array}\right]^{-1} \times\left[\begin{array}{c}
b_{10} \\
b_{20}
\end{array}\right]+\left[\begin{array}{cc}
1 & -b_{12} \\
-b_{21} & 1
\end{array}\right]^{-1} \times\left[\begin{array}{cc}
0 & b_{12} \\
b_{21} & 0
\end{array}\right]\left[\begin{array}{c}
y_{\mathrm{t}}-1 \\
z_{\mathrm{r}-1}
\end{array}\right]+} \\
& {\left[\begin{array}{cc}
1 & -b_{12} \\
-b_{21} & 1
\end{array}\right]^{-1} \times\left[\begin{array}{l}
u_{\mathrm{t}} \\
v_{\mathrm{t}}
\end{array}\right]}
\end{aligned}
$$

$\mathrm{B}^{-1} \mathrm{~B} \mathrm{X}_{\mathrm{t}}=\mathrm{B}^{-1} \Gamma_{0}+\mathrm{B}^{-1} \Gamma_{1} \mathrm{Xt}_{\mathrm{t}-1}+\mathrm{B}^{-1} \varepsilon_{\mathrm{t}}$

Yapılan çalışmada Türkiye için maliye ve para politikalarının iktisadi büyüme üzerindeki etkisi incelenmiştir. Bu çalışmada 2005:04-2020:02 yılları arasında iktisadi büyüme, para arzı ve gelir değişkenleri kullanılarak iktisadi büyümeye etkileri SVAR yöntemi yardımıla çeyreklik verilerle incelenmiştir. Analizde kullanılan değişkenler Türkiye Cumhuriyet Merkez Bankası (TCMB)'ndan alınmış olup, E-Views 10 paket programı kullanılmıştır. Yapılan çalışmaya ait model aşağıda gösterilmiştir:

Büyümeit $=\beta_{0}+\beta_{1}$ Para Arzlit $+\beta_{2}$ Gelirit $+u_{i t}$

(2.4) no'lu eşitlikte bağımlı değişken iktisadi büyüme ele alınmıştır.

Türkiye'de iktisadi büyüme, para arzı ve gelir değişkenlerine ait veri modeline ait tanımlayıcı istatistiki sonuçlar gösterilmiş ve birim kök testleri yapılarak model tahmini sonucu raporlanmıştır. Yapılan çalı̧̧mada 
ADF ve Philips-Perron birim kök testleriyle durağanlıkları yapılmıştır. Hemen sonrasında hata düzeltme modeli aracilığıyla kısa ve uzun dönem katsayıları tahmin edilmiştir.

\section{Ampirik Sonuçlar}

Íktisadi Büyüme Modeline Ait Birim Kök Testleri: Zaman serisi modelleri kullanılarak yapılan incelemelerde serilerin durağanlık derecelerini ve hangi seviyede durağan olduklarının incelenmesi önemlidir. Bir serinin durağanlı seviyesinin tespit edilmesinde kullanılan teknikler arasında birim kök testleri gelmektedir. Birim kök testi (2.5) no'lu eşitlikte belirtilmiş ve $\varrho$ 'nin $\varrho=0$ olma durumu sınanmıştır;

$$
\Delta y i t=\beta_{1}+\beta_{2 t}+Q_{i t-1}+u_{i t}
$$

(2.5) no'lu eşitlikte $\varrho=0$ sonucuna ulaş1lırsa, " $y$ t değişkeninin birim kökü vadır" sonucunu elde ederiz.

ADF Birim Kök Testi: Durağanlık, bir veri setinin geçmiş şoklardan kendisine ait zaman içerisinde azalan miktarda etkilenmesi veya zaman içerisinde veri setinin beklenen değeri içerisinde dalgalanmasını ifade etmektedir. Nedensellik analizi yapılmadan önce değişkenler için birim kök testlerinin yapılması gerekmektedir. Bu bağlamda çalışmanın bu bölümünde birim kök testi uygulanmıştır.

Tablo 3.1. ADF Birim Kök Test Sonuçları

\begin{tabular}{lllll} 
& Değişkenler & $\begin{array}{l}\text { Sabitli } \\
\text { Model }\end{array}$ & $\begin{array}{l}\text { Sabitli Trendli } \\
\text { Model }\end{array}$ & $\begin{array}{l}\text { Sabitsiz Trendsiz } \\
\text { Model }\end{array}$ \\
& \multirow{2}{*}{ Íktisadi Büyüme } & $\begin{array}{l}-6.751436 \\
(0.0000)\end{array}$ & $\begin{array}{l}-6.616890 \\
(0.0000)\end{array}$ & $\begin{array}{l}-1.862204 \\
(0.0601)\end{array}$ \\
& & 1.760463 & -1.345783 & 5.264434 \\
Seviyesinde & Gelir & $(0.9996)$ & $(0.8662)$ & $(1.0000)$ \\
& & 1.316450 & 6.885691 & 0.289522 \\
Birinci & Para Arzı & $(0.9985)$ & $(1.0000)$ & $(0.7662)$ \\
Derece & & -5.583972 & -6.469101 & -1.552305 \\
Farkı & D(Gelir) & $(0.0000)$ & $(0.0000)$ & $(0.1124)$ \\
& & 3.958565 & 3.319737 & 3.683706 \\
İkinci Derece Farkı & D(Para Arzı) & $(1.0000)$ & $(1.0000)$ & $(0.9999)$ \\
& D2(Para Arzı) & -10.97599 & -11.61051 & -10.80456 \\
& & $(0.0000)$ & $(0.0000)$ & $(0.0000)$ \\
\hline
\end{tabular}

NOT: Hücrelerdeki ilk değer Augmented Dickey Fuller test istatistiğini, parantez içindeki değger ise olasılık değerini göstermektedir. \%10 anlam düzeyinde ele alınmıştır. 
ADF birim kök testi sabitsiz-trendsiz, sabitli-trendsiz ve sabitli-trendli olmak üzere üç farklı modele göre durağanlığı test etmektedir. ADF birim kök testini uygularken iktisadi büyüme, gelir ve para arzı verilerinden yararlanılmıştır. Buradaki modeller ile Tablo 3.1'deki analiz sonuçlarına ulaşılmıştır.

\section{Testin Hipotezleri:}

H0: $\alpha=0$ Seride birim kök sorunu vardır.

H1: $\alpha \neq 0$ Seride birim kök sorunu yoktur.

Elde edilen sonuçlar seviyesindeki seriler için, sabitli model, sabitli trendli model ve sabitsiz trendsiz modellerde \%10 istatistiksel anlamlılık düzeylerinde test edilmiştir. ADF birim kök test sonuçlarına göre iktisadi büyüme değişkeni seviyesinde durağanken, diğer değişkenler seviyesinde durağan olmadıkları tespit edilmiştir.

Gelir ve para arzı serilerinin durağan olmadığı sonucuna ulaşılmasıyla birlikte seriyi durağan hale getirmek için birinci derece farkı alınarak sabitli model, sabitli trendli model ve sabitsiz trendsiz modellerde $\% 10$ istatistiksel anlamlılık düzeylerindeki tekrar test edilmiş ve gelir değişkeni birinci derecede durağan çıkarken, para arzı değişkeni birinci derecede durağan olmadığı sonucu gözlemlenmiştir. Para arzı değişkenini durağan hale getirmek için ikinci derece farkı alınarak sabitli model, sabitli trendli model ve sabitsiz trendsiz modellerde \%10 istatistiksel anlamlılık düzeylerinde yeniden test edilmiş ve para arzı değişkeninin ikinci derecede durağan oldukları tespit edilmiştir.

Philips-Perron Birim Kök Testi: ADF birim kök testlerinde hata terimlerinde beyaz gürültü koşulunun sağlanması amacıyla gecikme sayıları arttırılmaktadır. Bu bağlamda, $\Delta \mathrm{Y}_{\mathrm{t}}^{\prime}$ nin aşırı derecede gecikmeleri modele dahil edilmektedir. Schwert (1989) Monte Carlo incelemesinde otokorelasyon sorununu düzeltme seviyesinin örneklem büyüklükleri yoluyla arttırılamadığı durumlarında testlerde boyut bozuklukları meydana geldiğini gözlemlemiştir.

Bu gibi sorunlar neticesinde Philips Perron (1988) ADF birim kök testlerini genelleştirerek hata terimlerini bağımlı ve değişen varyans sorunlarının giderilmesinde kullanmıştır. Dolayısıyla Philip Perron (PP) birim 
kök testlerinde hata terimlerine ait varsayımlar diğer testlere oranla daha esnek yapıdadır.

Tablo 3.2. Philips-Perron Birim Kök Test Sonuçları

\begin{tabular}{lllll}
\hline & Değişkenler & Sabitli Model & $\begin{array}{l}\text { Sabitli Trendli } \\
\text { Model }\end{array}$ & $\begin{array}{l}\text { Sabitsiz Trendsiz } \\
\text { Model }\end{array}$ \\
\hline \multirow{3}{*}{ Seviyesinde } & İktisadi Büyüme & -6.751436 & -6.616890 & -3.193477 \\
& & $(0.0000)$ & $(0.0000)$ & $(0.0019)$ \\
& Gelir & 1.916526 & -1.308442 & 5.658848 \\
& & $(0.9998)$ & $(0.8760)$ & $(1.0000)$ \\
& Para Arzı & 5.365439 & 5.063034 & 5.884805 \\
Birinci & & $(1.0000)$ & $(1.0000)$ & $(1.0000)$ \\
Derece & D(Gelir) & -6.241832 & -6.420519 & -4.348112 \\
Fark1 & & $(0.0000)$ & $(0.0000)$ & $(0.0000)$ \\
& D(Para Arzı) & 0.679997 & -1.155572 & 1.906119 \\
İkinci Derece & D2(Para Arzı) & $(0.9907)$ & $(0.9098)$ & $(0.9855)$ \\
Fark1 & & $(0.00000)$ & -11.26732 & -10.46847 \\
\hline
\end{tabular}

Not: Hücrelerdeki ilk değger Philips-Perron (PP) test istatistiğini, parantez içindeki değer ise olasılık değerini göstermektedir. \%10 anlam düzeyinde ele alınmıştır.

\section{Testin Hipotezleri:}

H0: $\alpha=0$ Seri durağan değildir.

Ha: $\alpha<0$ Seri durağandır.

Elde edilen sonuçlar seviyesindeki seriler için, sabitli model, sabitli trendli model ve sabitsiz trendsiz modellerde \%10 istatistiksel anlamlılık düzeylerinde test edilmiştir. ADF birim kök test sonuçlarına göre iktisadi büyüme değişkeni seviyesinde durağanken, diğer değişkenler seviyesinde durağan olmadıkları tespit edilmiştir.

Gelir ve para arzı serilerinin durağan olmadığı sonucuna ulaşılmasıyla birlikte seriyi durağan hale getirmek için birinci derece farkı alınarak sabitli model, sabitli trendli model ve sabitsiz trendsiz modellerde $\% 10$ istatistiksel anlamlılık düzeylerindeki tekrar test edilmiş ve gelir değişkeni birinci derecede durağan çıkarken, para arzı değişkeni birinci derecede durağan olmadığı sonucu gözlemlenmiştir. Para arzı değişkenini durağan hale getirmek için ikinci derece farkı alınarak sabitli model, sabitli trendli model ve sabitsiz trendsiz modellerde \%10 istatistiksel anlamlılık düzeylerinde yeniden test edilmiş ve para arzı değişkeninin ikinci derecede durağan oldukları tespit edilmiştir. 
Gecikme Uzunluğunun Belirlenmesi: VAR modellerinin tanımlanmasında kritik unsur, modelde kullanılan serilerin gecikme uzunluğunun aşağıdaki gibi belirlenmesidir.

Tablo 3.3. Gecikme Uzunluğunu Belirleme

\begin{tabular}{lllllll}
\hline Lag & LogL & LR & FPE & AIC & SC & HQ \\
\hline $\mathbf{0}$ & 2217.666 & NA & $2.49 \mathrm{e}+33$ & 85.41023 & 85.52280 & 85.45338 \\
$\mathbf{1}$ & 1966.216 & 464.2153 & $2.22 \mathrm{e}+29$ & 76.08523 & $\mathbf{7 6 . 5 3 5 5 2 *}$ & $\mathbf{7 6 . 2 5 7 8 6 *}^{*}$ \\
$\mathbf{2}$ & 1961.100 & 8.854845 & $2.59 \mathrm{e}+29$ & 76.23461 & 77.02261 & 76.53671 \\
$\mathbf{3}$ & 1949.998 & 17.93445 & $2.41 \mathrm{e}+29$ & 76.15375 & 77.27947 & 76.58532 \\
$\mathbf{4}$ & 1946.388 & 5.414480 & $3.02 \mathrm{e}+29$ & 76.36107 & 77.82450 & 76.92212 \\
$\mathbf{5}$ & 1935.740 & 14.74383 & $2.92 \mathrm{e}+29$ & 76.29767 & 78.09882 & 76.98819 \\
$\mathbf{6}^{*}$ & 1918.369 & $\mathbf{2 2 . 0 4 7 0 3 *}$ & $\mathbf{2 . 2 1 e + 2 9 *}$ & $\mathbf{7 5 . 9 7 5 7 4 *}$ & 78.11460 & 76.79573 \\
$\mathbf{7}$ & 1909.881 & 9.794073 & $2.40 \mathrm{e}+29$ & 75.99542 & 78.47200 & 76.94488 \\
\hline
\end{tabular}

Not: AIC: Akaike Bilgi Kriteri, SC: Schwarz Bilgi Kriteri, HQ: Hannan-Quinn Bilgi Kriteri, LR: LR Test İstatistiği, FPE: Son Öngörü Hatası, ${ }^{*}$ Kritere göre belirlenen optimal gecikme uzunluğu

Yukarıdaki tabloda mevcut veriler 1şığında LR ve FPE kritik değerlerine göre gecikme uzunluğu altı olarak belirlenmiştir.

\section{VAR Analiz Sonuçları:}

VAR modelinde, hata terimlerinde otokorelasyon probleminin olmamas1 gerekmektedir. Bunun için otokorelasyon olup olmadığını belirten $H_{0}$ hipotezinin test edilebilmesi için LM testi kullanılır. Modelden ortaya çıkan sonuçların tutarlı olabilmesi için otokorelasyonun hangi gecikme uzunluğunda ortadan kalktığın bilinmesi gerekir.

Tablo 3.4. Otokorelasyon Test Sonuçları

\begin{tabular}{lllllll}
\hline Lag & LRE* stat & df & $\begin{array}{l}\text { Olasılık } \\
\text { Değeri }\end{array}$ & Rao F-stat & Df & $\begin{array}{l}\text { Olasılık } \\
\text { Değeri }\end{array}$ \\
\hline 1 & 9.304691 & 9 & 0.4096 & 1.049512 & $(9,70.7)$ & 0.4105 \\
2 & 9.795811 & 9 & 0.3673 & 1.108647 & $(9,70.7)$ & 0.3682 \\
3 & 9.630876 & 9 & 0.3812 & 1.088744 & $(9,70.7)$ & 0.3821 \\
4 & 22.27892 & 9 & 0.0080 & 2.750924 & $(9,70.7)$ & 0.0081 \\
5 & 5.713887 & 9 & 0.7682 & 0.628833 & $(9,70.7)$ & 0.7687 \\
$6^{*}$ & 8.884948 & 9 & 0.4480 & 0.999280 & $(9,70.7)$ & 0.4488 \\
7 & 0.880567 & 9 & 0.9997 & 0.093783 & $(9,70.7)$ & 0.9997 \\
\hline
\end{tabular}

Tablo 2.4'de belirtilen LM test sonuçlarma göre belirlenen gecikme uzunluğunun hata terimlerinde otokorelasyon problemi bulunmamaktadır. 
Tablo 3.5. White Test Sonuçlarn

\begin{tabular}{rll}
\hline Ki-Kare Test İstatistiği & Serbestlik Derecesi & Olasılık Değeri \\
\hline 232.4985 & 216 & 0.2100 \\
\hline
\end{tabular}

White testi "değişen varyans sorunu yoktur." biçimindeki boş hipotezi sınamaktadır. White testin verdiği ki-kare istatistik olasılık değeri $\% 10$ anlamlılık düzeyine göre değerlendirilerek karar verilmektedir. White testi sonucuna göre olasılık değeri 0.2100 bulunmuş ve \%10 anlamlılık düzeyinde $\mathrm{H}_{0}$ hipotezi reddedilemediğinden değişen varyans sorunu olmadığına karar verilmiştir.

\section{Vektör Hata Düzeltme Modeli}

Granger'e göre değişkenler arasında eşbütünleşme ilişkisinin söz konusu olması tek yönlü nedensellik ilişkisi olduğunu göstermekte ve serilerin uzun dönemde analizlerin standart hatalarının sağlıklı sonuçlar vermeyeceğini ve nedensellik ilişkisinin VAR analizi yerine hata düzeltme terimlerinin yer olduğu model kullanılarak analizlerin yapılması gerekmektedir (Yeşilkuş, 2019, s.115).

$Z_{t}$ modelde yer alan değişkenlerin vektörünü, $\varepsilon(n \times 1)$ çaplı rasgele hata terimleri vektörü, $A_{i}$ ise (nxn) çaplı katsayılar matrisi olmak üzere VAR modelini sağlayan denklem aşağıda gösterilmiştir:

$\Delta \mathrm{zt}=\Gamma \mathrm{i} \Delta \mathrm{zt}-1+\ldots+\Gamma \mathrm{i} \Delta \mathrm{zt}-\mathrm{i}+1+\pi \mathrm{zt}-\mathrm{k}+\mathrm{zt}$

(3.1) no'lu eşitlikte Vektör Hata Düzeltme Modelini temsil etmektedir. Hata Düzeltme modeline göre, $\Gamma, \mathrm{z}$ vektörünün birinci derecede farkını, I (nxn) çaplı birim matrisi temsil eden serilere ait katsayı matrisi $\Gamma_{\mathrm{i}}=-\left(\mathrm{I}-\mathrm{A}_{1}-\ldots-\mathrm{A}_{\mathrm{i}}\right) ;(\mathrm{i}=1 \ldots \mathrm{k}-1)$ ile $\pi=-\left(\mathrm{I}-\mathrm{A}_{1}-\ldots-\mathrm{A}_{\mathrm{k}}\right)$ olacak şekilde aşağıda gösterilmiştir:

$\Delta \mathrm{zt}=\Gamma \mathrm{i} \Delta \mathrm{zt}-1+\ldots+\Gamma \mathrm{i} \Delta \mathrm{zt}-\mathrm{i}+1+\pi \mathrm{zt}-\mathrm{k}+\mathrm{zt}$

eşitliği elde edilmektedir. Bu sayede uzun dönem bağlantılarını ifade etmekte olan $\pi$ ve kısa dönem bağlantılarını temsil eden Гi (3.2) no'lu denklemde belirtilmiştir. Buradan yola çlkılarak uzun döneme ait $\alpha$ ile $\alpha$ ve $\beta$ (nxr) çaplı matrisler uyarlama hılarını belirtmek ve uzun dönem $\beta$ 
parametresini ifade etmekte olan eşbütünleşme ilişkisinin varlığını belirten hipotez $\pi=\alpha \beta^{\prime}$ dır. Söz konusu hipotezin geçerlilik kazandığı bir koşulda, $\beta^{\prime}$ Zt ile ifade edilen doğrusal bileşimler durağan olduklarını göstermektedir.

Tablo 3.6. Hata Düzeltme Modeline Ait Denklem Sonuçları

\begin{tabular}{lc}
\hline Cointegrating Eq: & CointEq1 \\
\hline BUYUME_SA(-1) & 1.000000 \\
\hline & $1.79 \mathrm{E}-08$ \\
GSYH_SA(-1) & $(1.9 \mathrm{E}-08)$ \\
& {$[0.92214]$} \\
\hline & $1.32 \mathrm{E}-08$ \\
PARZI_SA(-1) & $(3.1 \mathrm{E}-08)$ \\
& {$[0.42237]$} \\
\hline C & -17.12213 \\
\hline
\end{tabular}

Tablo 3.7. Hata Düzeltme Modeline Ait Denklem Sonuçları (devamı)

\begin{tabular}{|c|c|c|c|}
\hline Error Correction: & D(BUYUME_SA) & D(GSYH_SA) & D(PARZI_SA) \\
\hline \multirow{3}{*}{ CointEq1 } & 1.104321 & 8035504 & 1229538. \\
\hline & $(0.46337)$ & $(2571664)$ & $(3853786)$ \\
\hline & [ 2.38326] & [3.12463] & [0.31905] \\
\hline \multirow{3}{*}{ D(BUYUME_SA(-1)) } & -1.194353 & -5754928 & -2006550 \\
\hline & $(0.60634)$ & (3365145) & $(5042864)$ \\
\hline & {$[-1.96979]$} & {$[-1.71016]$} & {$[-0.39790]$} \\
\hline \multirow{3}{*}{ D(BUYUME_SA(-2)) } & -0.837394 & -4618703. & 2786330 \\
\hline & $(0.57576)$ & (3195424) & $(4788527)$ \\
\hline & {$[-1.45443]$} & {$[-1.44541]$} & {$[0.58188]$} \\
\hline \multirow{3}{*}{ D(BUYUME_SA(-3)) } & -0.905874 & -3952614. & -1531584. \\
\hline & $(0.51717)$ & $(2870275)$ & $(4301273)$ \\
\hline & {$[-1.75160]$} & [-1.37709] & {$[-0.35608]$} \\
\hline \multirow{3}{*}{ D(BUYUME_SA(-4)) } & -1.299523 & -5614162. & -1303282 \\
\hline & $(0.49818)$ & $(2764884)$ & $(4143338)$ \\
\hline & {$[-2.60854]$} & {$[-2.03052]$} & {$[-0.31455]$} \\
\hline \multirow{3}{*}{ D(BUYUME_SA(-5)) } & -0.230825 & -675393.4 & -5334420 \\
\hline & $(0.38481)$ & $(2135686)$ & (3200448) \\
\hline & {$[-0.59984]$} & {$[-0.31624]$} & {$[-1.66677]$} \\
\hline \multirow{3}{*}{ D(BUYUME_SA(-6)) } & -0.278217 & -1496316 & 666769.4 \\
\hline & $(0.19388)$ & $(1076021)$ & $(1612479)$ \\
\hline & {$[-1.43500]$} & {$[-1.39060]$} & [0.41351] \\
\hline \multirow{3}{*}{ D(GSYH_SA(-1)) } & $-1.89 \mathrm{E}-07$ & -0.635950 & -0.959058 \\
\hline & $(1.0 \mathrm{E}-07)$ & $(0.57134)$ & $(0.85619)$ \\
\hline & {$[-1.83696]$} & {$[-1.11308]$} & {$[-1.12014]$} \\
\hline \multirow{3}{*}{ D(GSYH_SA(-2)) } & $-5.01 \mathrm{E}-08$ & 0.085528 & -1.335010 \\
\hline & $(1.1 \mathrm{E}-07)$ & $(0.62973)$ & $(0.94369)$ \\
\hline & {$[-0.44180]$} & [ 0.13582$]$ & {$[-1.41467]$} \\
\hline \multirow{3}{*}{ D(GSYH_SA(-3)) } & $2.76 \mathrm{E}-08$ & -0.107450 & 0.621529 \\
\hline & $(1.2 \mathrm{E}-07)$ & $(0.63996)$ & $(0.95902)$ \\
\hline & [ 0.23955$]$ & {$[-0.16790]$} & [0.64809] \\
\hline
\end{tabular}




\begin{tabular}{|c|c|c|c|}
\hline D(GSYH_SA(-4)) & $\begin{array}{r}5.07 \mathrm{E}-08 \\
(1.2 \mathrm{E}-07) \\
{[0.43983]}\end{array}$ & $\begin{array}{r}0.081254 \\
(0.63938) \\
{[0.12708]} \\
\end{array}$ & $\begin{array}{r}0.032205 \\
(0.95815) \\
{[0.03361]} \\
\end{array}$ \\
\hline D(GSYH_SA(-5)) & $\begin{array}{c}-3.11 \mathrm{E}-07 \\
(1.1 \mathrm{E}-07) \\
{[-2.88733]} \\
\end{array}$ & $\begin{array}{r}-1.604524 \\
(0.59850) \\
{[-2.68092]} \\
\end{array}$ & $\begin{array}{r}0.385733 \\
(0.89688) \\
{[0.43008]} \\
\end{array}$ \\
\hline D(GSYH_SA(-6)) & $\begin{array}{c}-8.51 \mathrm{E}-08 \\
(1.1 \mathrm{E}-07) \\
{[-0.78453]} \\
\end{array}$ & $\begin{array}{r}-0.398964 \\
(0.60203) \\
{[-0.66270]} \\
\end{array}$ & $\begin{array}{c}-1.451328 \\
(0.90218) \\
{[-1.60869]} \\
\end{array}$ \\
\hline D(PARZI_SA(-1)) & $\begin{array}{r}-9.41 \mathrm{E}-08 \\
(3.4 \mathrm{E}-08) \\
{[-2.79115]} \\
\end{array}$ & $\begin{array}{r}-0.840487 \\
(0.18707) \\
{[-4.49294]} \\
\end{array}$ & $\begin{array}{r}0.917043 \\
(0.28033) \\
{[3.27126]} \\
\end{array}$ \\
\hline D(PARZI_SA(-2)) & $\begin{array}{c}-1.04 \mathrm{E}-07 \\
(4.9 \mathrm{E}-08) \\
{[-2.12596]} \\
\end{array}$ & $\begin{array}{r}-1.012278 \\
(0.27259) \\
{[-3.71353]} \\
\end{array}$ & $\begin{array}{r}1.237513 \\
(0.40850) \\
{[3.02944]} \\
\end{array}$ \\
\hline D(PARZI_SA(-3)) & $\begin{array}{c}-1.05 \mathrm{E}-07 \\
(6.6 \mathrm{E}-08) \\
{[-1.59460]} \\
\end{array}$ & $\begin{array}{r}-0.578222 \\
(0.36566) \\
{[-1.58133]} \\
\end{array}$ & $\begin{array}{r}0.384069 \\
(0.54796) \\
{[0.70091]} \\
\end{array}$ \\
\hline D(PARZI_SA(-4)) & $\begin{array}{c}-1.00 \mathrm{E}-07 \\
(6.6 \mathrm{E}-08) \\
{[-1.51896]}\end{array}$ & $\begin{array}{r}-0.636540 \\
(0.36637) \\
{[-1.73744]}\end{array}$ & $\begin{array}{r}0.341640 \\
(0.54902) \\
{[0.62227]}\end{array}$ \\
\hline D(PARZI_SA(-5)) & $\begin{array}{c}3.40 \mathrm{E}-08 \\
(6.0 \mathrm{E}-08) \\
{[0.56762]}\end{array}$ & $\begin{array}{r}-0.151597 \\
(0.33249) \\
{[-0.45595]}\end{array}$ & $\begin{array}{r}0.462664 \\
(0.49825) \\
{[0.92857]}\end{array}$ \\
\hline D(PARZI_SA(-6)) & $\begin{array}{c}5.27 \mathrm{E}-08 \\
(6.9 \mathrm{E}-08) \\
{[0.76354]}\end{array}$ & $\begin{array}{c}0.444901 \\
(0.38314) \\
{[1.16121]}\end{array}$ & $\begin{array}{r}1.229072 \\
(0.57415) \\
{[2.14068]}\end{array}$ \\
\hline C & $\begin{array}{r}13.22227 \\
(5.33205) \\
{[2.47977]}\end{array}$ & $\begin{array}{r}94784876 \\
(3.0 \mathrm{E}+07) \\
{[3.20298]}\end{array}$ & $\begin{array}{r}13260269 \\
(4.4 \mathrm{E}+07) \\
{[0.29902]}\end{array}$ \\
\hline
\end{tabular}

Tablo 3.6 ve Tablo 3.7'de Vektör Hata Düzeltme Modeli sonuçları gösterilmiştir. Tablolardaki kalın yazı stiliyle belirtilmekte olan sonuçlar eşbütünleşme denkleminin sonuçlarıdır. Tablo 3.6 ve Tablo 3.7' de kalın yazı stiliyle belirtilen birinci sütun ise hedeflenmekte olan modeli göstermektedir. Hedeflenen modelde iktisadi büyüme bağımlı değişken olup, tüm değişkenlerin altıncı gecikmeleri yer almaktadır.

Grafik 3.1'de yapısal kırılmaları gösteren Cusum Test grafiği gösterilmiştir. Cusum test sonuçlarında kırmızı çizgiler üzerinde herhangi bir taşma olmadığından modelde yapısal kırılma olmadığ görülmektedir. Model kuruldukdan sonra Granger nedensellik analizi yapılmıştır. $\mathrm{Bu}$ analize ait sonuçlar Tablo $3.8^{\prime}$ de verilmektedir. Tablo 3.8'e göre gelir ile para arzı arasında çift yönlü bir nedensellik ilişkisi söz konusuyken, gelir ile iktisadi büyüme arasında herhangi bir nedensellik ilişkisi tespit edilememiştir. Nedensellik bulguları neticesinde maliye ve 
para politikalarının Türkiye'de iktisadi büyümeyi pozitif yönde etkilediği sonucu gözlemlenmiştir. Bu Bağlamda elde edilen sonuç iktisat kuramına uygun olduğu sonucuna varılmaktadır.

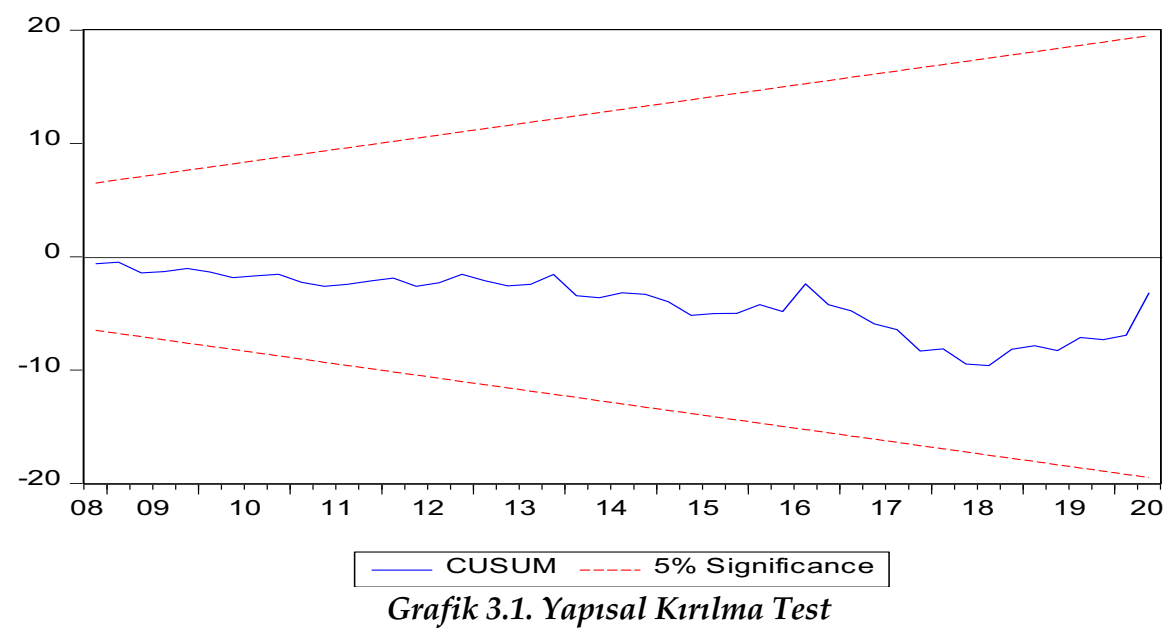

Granger nedensellik analizi söz konusu etkilerin düzeyleri hakkında net sonuçlar vermediğinden dolayı etki-tepki fonksiyonları ile varyans ayrıştırması analizine başvurulmuştur.

Tablo 3.8. Granger Nedensellik Analiz Sonuçları

\begin{tabular}{llll}
\hline Bağımlı Değişken: İktisadi Büyüme & & & \\
\hline Değiskkenler & Chi-sq & df & Olasılık Değeri \\
GSYH_SA & 9.597970 & 6 & 0.1426 \\
PARZI_SA & 30.98131 & 6 & 0.0000 \\
Bağımlı Değissken:Gelir & & & \\
IKKTİSADİ BÜYÜME_SA & 6.582416 & 6 & 0.3612 \\
PARA ARZI_SA & 78.04552 & 6 & 0.0000 \\
Bağımlı Değišken:Para Arzı & & & \\
IKTTISADİ BÜYÜME_SA & 5.702003 & 6 & 0.4574 \\
GSYH_SA & 16.75703 & 6 & 0.0102 \\
\hline
\end{tabular}




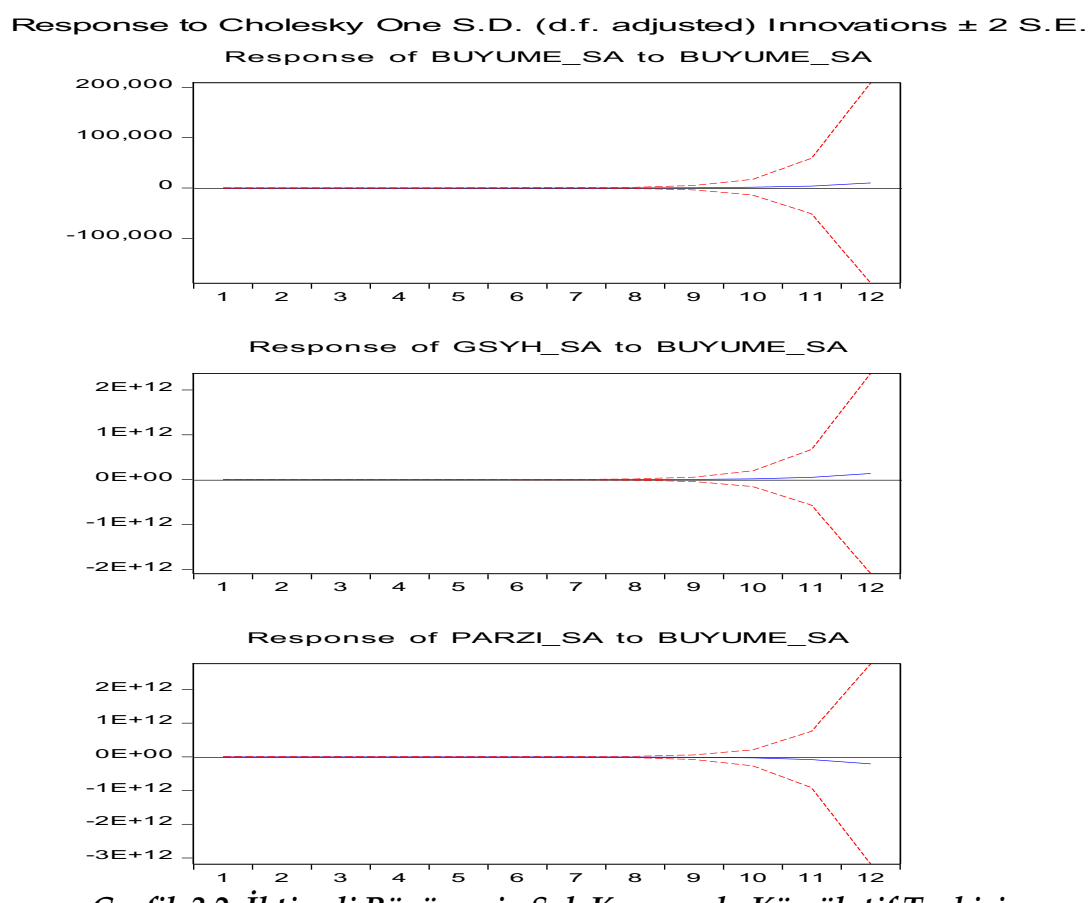

Grafik 3.2 İktisadi Büyümenin Şok Karşısında Kümülatif Tepkisi

Büyüme değişkeninde bir standart sapmalık şoka karşılık gelir değişkeni ilk on ay herhangi bir tepki vermemiştir. On birinci aydan itibaren pozitif artan yönde tepki vermeye başlamıştır.

Büyüme değişkeninde bir standart sapmalık şoka karşılık para arzı değişkeni ilk on ay herhangi bir tepki göstermemiştir. On birinci aydan itibaren negatif azalan yönde tepki vermeye başlamıştır.

Tablo 3.9. Varyans Ayrıştırma Sonuçları (iktisadi büyüme)

\begin{tabular}{llll}
\hline Dönem & İktisadi Büyüme & Gelir & Para Arzi \\
\hline $\mathbf{1}$ & 100.0000 & 0.000000 & 0.000000 \\
$\mathbf{2}$ & 87.39382 & 3.589502 & 9.016677 \\
$\mathbf{3}$ & 44.61930 & 12.81125 & 42.56945 \\
$\mathbf{4}$ & 23.52506 & 28.21527 & 48.25967 \\
$\mathbf{5}$ & 15.76334 & 33.08579 & 51.68535 \\
$\mathbf{6}$ & 15.76334 & 31.19437 & 53.04229 \\
$\mathbf{7}$ & 16.13502 & 32.12792 & 51.73706 \\
\hline
\end{tabular}


Tablo 3.9'da iktisadi büyümenin varyans ayrıştırma sonuçları gösterilmektedir. Tablo 3.9'a göre iktisadi büyüme değişkeninin birinci dönem sonu itibariyle varyans değişimi \%100'ü kendisinden kaynaklanmakta iken ikinci dönem sonu itibarıla \%87.9'u kendisinden, \%3.58'i gelirden ve \%9.01'i para arzından kaynaklanmaktadır. Yedinci dönem itibariyle ise iktisadi büyüme değişkeninin varyans değişimi \%16.13'ü kendisinden, \%32.12'si gelirden ve \%51.73'ü para arzı tarafından açıklanmaktadır.

Tablo 3.10. Varyans Ayrıştırma Sonuçları (gelir)

\begin{tabular}{llll}
\hline Dönem & İktisadi Büyüme & Gelir & Para Arz1 \\
\hline $\mathbf{1}$ & 85.02897 & 14.97103 & 0.000000 \\
$\mathbf{2}$ & 63.04313 & 26.65617 & 10.30070 \\
$\mathbf{3}$ & 37.80301 & 28.89353 & 33.30346 \\
$\mathbf{4}$ & 25.61798 & 30.53073 & 43.85129 \\
$\mathbf{5}$ & 18.77700 & 32.15744 & 49.06557 \\
$\mathbf{6}$ & 16.97754 & 31.67894 & 51.34352 \\
$\mathbf{7}$ & 16.48974 & 31.91946 & 51.59108 \\
\hline
\end{tabular}

Tablo 3.10'da gelir değişkenine ait varyans ayrıştırma sonuçları gösterilmektedir. Tablo 3.10’a göre gelir değişkeninin birinci dönem sonu itibariyle varyans değişimi \%14.97'si kendisinden, \%85.02'si iktisadi büyümeden kaynaklanmakta iken ikinci dönem sonu itibarryla $\% 26.65$ 'i kendisinden, \%63.04'ü iktisadi büyümeden ve \%10.30'u para arzından kaynaklanmaktadır. Yedinci dönem itibariyle ise gelir değişkeninin varyans değişimi \%31.91'i kendisinden, \%16.48'i iktisadi büyümeden ve $\% 51.59$ 'u para arzı tarafından açıklanmaktadır.

Tablo 3.11. Varyans Ayrıştırma Sonuçları (para arzı)

\begin{tabular}{llll}
\hline Dönem & İktisadi Büyüme & Gelir & Para Arz1 \\
\hline $\mathbf{1}$ & 1.534553 & 21.80538 & 76.66007 \\
$\mathbf{2}$ & 8.695040 & 24.64073 & 66.66423 \\
$\mathbf{3}$ & 12.49660 & 31.16970 & 56.33370 \\
$\mathbf{4}$ & 14.87027 & 31.89622 & 53.23352 \\
$\mathbf{5}$ & 15.88045 & 32.13836 & 51.98119 \\
$\mathbf{6}$ & 16.19287 & 32.03984 & 51.76730 \\
$\mathbf{7}$ & 16.12466 & 32.03039 & 51.84495 \\
\hline
\end{tabular}

Tablo 3.11'de para arzı değişkenine ait varyans ayrıştırma sonuçları gösterilmektedir. Tablo 3.11'e göre para arzı değişkeninin birinci dönem 
sonu itibariyle varyans değişimi \%76.66'sı kendisinden, \%1.53'ü iktisadi büyümeden ve \%21.80'i gelirden kaynaklanmakta iken ikinci dönem sonu itibarıla \%66.66'sı kendisinden, \%8.69'u iktisadi büyümeden ve \%24.64'ü gelirden kaynaklanmaktadır. Yedinci dönem itibariyle ise para arzı değişkeninin varyans değişimi \%51.84'ü kendisinden, \%16.12'si iktisadi büyümeden ve \%32.03'ü gelir tarafından açıklanmaktadır.

\section{Sonuç}

Herhangi bir ülkede uygulanan iktisat politikaların etkili olup olmadığının bilinmesi model alma açısından çok önemlidir Özellikle, iktisadi krizlerle karşılaşan bir ekonomide, krizden çıkmak için hazırlanan ve kararlılıkla uygulanacak iktisadi reçeteler oldukça önemlidir. Hazırlanan ve uygulanması gereken iktisadi reçetelerde, ülke ekonomisinde faydalı ve etkin olacak iktisadi politika ve araçları büyük önem taşımaktadır. Bu çalışmada, Türkiye ekonomisinde yaşanan ekonomik krizlerde para ve maliye politikalarından hangisinin daha etkin olduğu incelenmiştir.

Çalışmada Türkiye'de maliye ve para politikalarının etkinliği 2005:042020:02 dönemine ilişkin çeyreklik verilerle ve yapısal SVAR modeli yardımıyla incelenmiştir. Genel bir değerlendirme yapılırsa, Türkiye'de incelenen dönemlerde hem maliye hem de para politikalarının etkin olduğu sonucuna ulaşılmıştır.

Yapısal SVAR modelinde iktisadi performansın göstergesi olarak iktisadi büyüme, para politikasının göstergesi olarak TCMB'nin para arzı, maliye politikasının göstergesi olarak da gelir kullanılmıştır. Söz konusu değişkenler arasındaki ilişki ise VAR modeline dayalı Granger nedensellik analizi, etki-tepki fonksiyonları ve varyans ayrıştırması ile incelenmiştir. Granger nedensellik analizinde para arzı ile gelir arasında çift yönlü bir nedensellik ilişkisi söz konusuyken, iktisadi büyüme ile gelir arasında herhangi bir ilişki söz konusu değildir. Bu durum Türkiye'de para politikasının ve maliye politikasının iktisadi büyümeyi pozitif etkilediğini göstermektedir. Etki-tepki fonksiyonları İktisadi büyümeye bir standartlık şok karşısında gelir ve para arzı pozitif ile negatif ve istatistiksel olarak anlamlı bir tepki verdiğini göstermektedir. Bu bağlamda gelir, pozitif bir tepki verdiğinden dolayı maliye politikası para politikasına nazaran daha etkin olduğu anlamını taşımaktadır. 
Varyans ayrıştırması sonuçlarında iktisadi büyümenin varyansının açıklanmasında gelir ve para arzı değişkenlerinin yaklaşık olarak birbirlerine yakın değerlere sahip oldukları görülmüştür. Ancak para arzının payı hızlı yükselirken gelirin payı yavaş yükselmiştir. Bu sonuçlara göre para politikasının iktisadi büyümede, maliye politikasına kıyasla daha etkili olduğu rahatlıkla söylenebilir. 


\title{
EXTENDED ABSTRACT \\ Relative Effectiveness of Monetary and Fiscal Policy in Turkey: SVAR Analysis
}

\author{
İzzeetin Ulusoy \\ Hatay Mustafa Kemal University
}

Economic policies are the efforts of governments to achieve certain economic goals by using economic instruments. Objectives targeted by economic policies; rapid economic growth, high employment and price stability. In this context, the policies and tools used to achieve the determined targets are fiscal and monetary policies. Monetary policies; These are the strategies created to reach the main economic goals by influencing the cost and amount of money, the expectations of households and companies. Fiscal policies are the arrangements that must be made in the size and composition of public revenues and expenditures in order to achieve basic economic goals.

The need for economic policies is at the forefront of discussions at the macroeconomic level. Recently, discussions between New Classical Theory and Keynesian Theory have been made over monetary policies and fiscal policies have not been taken into account. The relative effectiveness of fiscal and monetary policies is discussed by economists, but there is no consensus on this issue yet. Kenesian-Monetarist debates are at the heart of the subject. While the Keynesian school gives importance to fiscal policy, the Monetaris school gives importance to monetary policy. It is one of the topics discussed in the economic literature that fiscal or monetary policies are more effective and valid in achieving economic policy goals. This issue was constantly discussed by Monetarist and Keynesian economists in the 1960s and 1970s.

In these discussions, Keynesian economists claimed that fiscal policies were more effective, while Monetarist economists claimed that monetary policies were more effective. In addition, there are Keynesian economists who argue that monetary policies are ineffective in achieving economic policy goals, and there are Monetarist economists who argue that fiscal 
policies are ineffective. In this context, many empirical studies were conducted in the 1960s and 1970s. Today, although there are not many economists who have negative opinions on the effectiveness of fiscal and monetary policies as a result of these studies, discussions on the relative effectiveness of these two policies continue.

Knowing whether the economic policies implemented in any country are effective is very important in terms of being a model. Especially in an economy facing economic crises, the economic prescriptions prepared to get out of the crisis and to be applied decisively are very important. Economic policies and tools that will be useful and effective in the country's economy are of great importance in the economic prescriptions that are prepared and to be applied. In this study, it has been examined which of the monetary and fiscal policies is more effective in the economic crises experienced in the Turkish economy.

Monetarist and Keynesian economists have different views on fiscal and monetary policy efficiencies, differing views on money demand and interest rate elasticity of investments. While Keynesian economists argue that money demand has high interest rate elasticity and investments have low interest rate elasticity, Monetarist economists argue the opposite. If the interest elasticity of money demand is high and the interest elasticity of investments is low, an increase in the money supply will lead to a large decrease in the interest rate. However, these decreases in interest rates will stimulate investments to a limited extent. In this context, increasing public expenditures or reducing taxes with fiscal policies will increase aggregate demand more than monetary policies.

If the interest elasticity of money demand is low and investment is high, any increase in the money supply will lead to a limited fall in the interest rate. However, these decreases in the interest rate will stimulate investments more. From this point of view, it can be said that monetary policies are effective. Therefore, fiscal policies are ineffective because of the increase in interest rates, reducing some private sector investments and causing the crowding out effect.

In the study, the effect of fiscal and monetary policies on economic growth in the Turkish economy was examined. Economic growth, money supply and income variables including quarterly data between 2005:04-2020:02 are used. With the help of these variables, the effects of 
monetary and fiscal policies on economic growth were examined with the SVAR method. The variables used in the analysis were obtained from the Central Bank of the Republic of Turkey, and the E-Views 10 package program was used.

In the first part of the study, the literature study was mentioned. In the second part, the methods and data sets used in the study are explained. In the third chapter, empirical analysis results are explained. In the last part, the analysis results of the study were interpreted and the results were evaluated.

In the structural SVAR model, economic growth is used as an indicator of economic performance, the CBRT's money supply as an indicator of monetary policy, and income as an indicator of fiscal policy. The relationship between the mentioned variables was examined with Granger causality analysis based on the VAR model, impulse-response functions and variance decomposition. While there is a bidirectional causality relationship between money supply and income in Granger causality analysis, there is no relationship between economic growth and income.

This situation shows that both monetary policy and fiscal policy positively affect economic growth in Turkey. Impulse-response functions show that economic growth comes in response to a standard shock and the money supply has a positive to negative and statistically significant response. In this context, it means that fiscal policy is more effective than monetary policy, since income gives a positive response. In the variance decomposition results, it has been seen that the income and money supply variables have approximately close values in explaining the variance of economic growth. However, while the share of money supply increased rapidly, the share of income increased slowly. According to these results, it can be easily said that monetary policy is more effective in economic growth than fiscal policy.

\section{Kaynakça / References}

Ataç, B. (2009). Maliye politikası: Gelişimi, Amaçları, Araçları ve Uygulama sorunları. Ankara: Turhan Kitabevi. 
Cengiz, V. (2008). Keynesyen ve Monetarist görüşte parasal aktarım mekanizması: Bir karşılaştırma. Atatürk Üniversitesi İktisadi ve İdari Bilimler Dergisi, 2(1), 115 - 127

Dikmen, N. (2006). Nominal GSUH ve politika tercihi: St. Louis Model uygulaması. Atatürk Üniversitesi İktisadi ve İdari Bilimler Dergisi, 20(2), 87105.

Fischer, S. and Rudiger, D. (1998). Makroekonomi, Çev. Salih Ak, Mahir Fisunoğlu, Refia Yıldırım (1996), McGraw-Hill - Akademi

Karaca, O. (2017). Türkiye'de para ve maliye politikalarının göreli etkinliği: var analizi. Uluslararası Yönetim İktisat ve İşletme Dergisi, ICMEB17 Özel Sayısı, 227-240

Hall, S., Henry, B. and Nixon, J.(1999). Central Bank independence and coordinating monetary and fiscal policy. Economic Outlook, 23(2), 7-13, https://doi.org/10.1111/1468-0319.00162

Hanif, M. and Arby, M. (2003). Monetary and fiscal policy coordination. Munich Personal Repec, Archive, No: 10307.

Kretzmer, P. (1992). Monetary vs. fiscal policy: New evidence on an old debate. Federal Reserve Bank of Kansas City Economic Review, 77(2), 21-30.

Kutlar A. (2007). Ekonometriye giriş. Ankara: Nobel Yayın Dağıtım

Önder, T. (2005). Para politikası araçları amaçları ve Türkiye uygulaması. Uzman Yeterlilik Tezi. TCMB Piyasalar Genel Müdürlüğü, Ankara

Panico, C. and Suarez, V. (2008). Policy coordination in the Euro Area, https://papers.ssrn.com/sol3/papers.cfm?abstract_id=1265677, 5-35. Erişim Tarihi, 19.12.2020

Saraç, T.B. (2012). Kayıtdışı ekonomi ve işsizlik ilişkisi Türkiye Örneği. Sosyoekonomi Dergisi, 2012(2), 81-103

TCMB (2020). https://evds2.tcmb.gov.tr/index.php?/evds/dashboard/311, Erişim Tarihi: 04.09.2020

Yeşilkuş, M.S, (2019). Enerji ve ekonomik büyüme ilişkisi: Net ithalatçı ve net ihracatçı ülkeler üzerine ampirik bir analiz. Yüksek Lisans Tezi. Bülent Ecevit Üniversitesi, Sosyal Bilimler Enstitüsü, İktisat Anabilim Dalı, Zonguldak 


\section{Kaynakça Bilgisi / Citation Information}

Ulusoy, İ. (2021). Türkiye'de Para ve Maliye Politikalarının Göreli Etkinliği: SVAR Analizi. OPUS-Uluslararası Toplum Araştırmaları Dergisi, 18(Yönetim ve Organizasyon Özel Sayıs1), 1735-1757. DOI: 10.26466/opus.802682. 